\title{
¿Recuperar un lugar para la ética en un mundo sin referentes? Ética discursiva, normatividad y política según Jürgen Habermas
}

\author{
Pablo Salvat*
}

La ciencia melancólica de la que ofrezco a mi amigo algunos fragmentos, se refiere a un ámbito que desde tiempos inmemoriales se consideró el propio de la filosofía, pero que desde la transformación de ésta en método cayó en la irreverencia intelectual, en la arbitrariedad sentenciosa y, al final, en el olvido: la doctrina de la vida recta. Lo que en un tiempo fue para los filósofos la vida, se ha convertido en la esfera de lo privado, y aun después simplemente del consumo, que como apéndice del proceso material de la producción se desliza con éste sin autonomía y sin sustancia propia

THeOdor W. Adorno

* Doctor en Filosofía Universidad Católica de Lovaina, Bélgica; investigador Centro de Ética (Filosofía y Humanidades) Universidad Alberto Hurtado; director Magíster de Ética Social y Desarrollo Humano (Departamento de Ciencias Políticas y Relaciones Internacionales) Universidad Alberto Hurtado. E-mail: psalvat@uahurtado.cl. Este artículo forma parte de las actividades de investigación del Proyecto No 1040266, "Dilemas éticos/valóricos de la sociedad chilena en el marco del proceso de diferenciación y autonomía del sistema jurídico", realizado en conjunto con el profesor de la Escuela de Sociología de la Universidad Alberto Hurtado, Aldo Mascareño (doctor en Sociología, Universidad de Bielefeld). Con algunas modificaciones, los elementos esenciales de estas notas provienen de este proyecto. 


\begin{abstract}
RESUMEN
El proceso de modernización, en sus distintas expresiones — derecho, política, cultura-, al autonomizar y diferenciar sus esferas de acción y justificación, plantea la necesidad y pertinencia de interrogarse por las posibles fuentes de los valores y normas legitimantes en esas esferas, en medio de un nuevo politeísmo axiológico y del pluralismo de visiones de fondo. La debilidad de la política y el malestar con el presente conforman el contexto de esa interrogante. ¿Cómo y desde dónde obtener criterios compartibles universalizables para criticar el presente — sus instituciones - y validarlo como justo o injusto, bueno o malo, deseable o indeseable? Las respuestas no son sencillas. En función de este problema nos interesa examinar algunos rasgos de la propuesta habermasiana. La reflexión de Habermas resulta valiosa toda vez que se hace desde materiales interdisciplinarios y, al mismo tiempo, desde la asunción de una tensión que no puede ser eliminada entre el momento fáctico y el normativo, constitutivos ambos de los distintos plexos de realidades de lo humano. Leemos su propuesta de ética discursiva como un esfuerzo por abrir un lugar legítimo a una normatividad que busca su universabilidad en la interacción comunicativa presente y reconstruible en los mundos de vida. A partir de allí examinamos algunos elementos que conforman su ética discursiva, como oferta de una ética ocupada con los intereses generalizables, expresables y consensuables en un espacio público. Por último, efectuamos algunas reflexiones sobre esa normatividad comunicativamente establecida y sus puentes de ida y vuelta hacia el derecho y la política.
\end{abstract}

Palabras clave

- Normatividad • ética del discurso • validez universal • política • deliberación

\title{
En busca de un lugar para la ética normativa en culturas descentradas
}

Al preguntarnos por el devenir de la aparentemente necesaria y deseable autonomización y diferenciación del sistema jurídico en la marcha de Chile —en particular, después de la experiencia autoritaria y de violación a los derechos humanos-, y por las nuevas exigencias modernizadoras y democratizadoras de la vida política del país, hay que hacer frente al tema de la normatividad legitimante y su eventual proveniencia, en el entendido de que en el espacio público y en el mundo de la vida, ninguna visión de fondo (filosófica) puede tener garantizada a priori un lugar preferencial en la actualidad. Ello porque, dicho de otro modo, somos parte de un proceso de transición que afecta no solamente la reconstrucción del sistema democrático y jurídico, sino también la conformación y constelación de valores y normas que alimentan la integración social (cf. Salvat 2000). Lo importante en esto es que esa modernización y sus procesos de autonomización y diferenciación de esferas de acción y validación, conllevan la fragmentación de cualquier ideario ético-normativo que se pretendiese base uniforme y homogénea para la justificación de la acción y la marcha de las instituciones. Este proceso, que comenzó hace ya 
varios siglos en el Occidente europeo, se ha visto acelerado en los últimos tiempos en nuestra América.

A través de dicho proceso de fragmentación se muestra la experiencia de la misma modernidad, desde la cual se consagra una progresiva diferenciación/escisión de la racionalidad sustantiva en distintas esferas autónomas de valor (verdad, justicia, belleza), las cuales no vienen soldadas ya previamente desde una visión metafísica o teológica. Por cierto, este proceso no se da en su puridad en el transcurso histórico de países y continentes. Sin embargo, en general puede decirse que las culturas occidentales modernas tienden a desplazar la presencia de lo sacro-religioso como cemento unificador exclusivo de la experiencia vital e institucional de las sociedades.

En la medida en que los parámetros modernizadores se hacen parte de las sociedades, se van diferenciando los sistemas (economía, derecho, política, educación), y se desligan de una tutela religiosa o de una autoridad externa. Es lo que ha ido sucediendo de manera aproximada en nuestras sociedades y culturas, aunque en ellas exista aún mucho de hibridaje. Con mayor o menor presencia de hibridaje, se han dado procesos de individuación, de universalización de normas morales y de cierta racionalización de las imágenes de mundo. ${ }^{1}$ A pesar de las dificultades y retardos concretos que puede experimentar esta situación entre nosotros, reflexivamente hablando no parece esperable ni plausible en el espacio público nacional ni en la marcha de las instituciones y sistemas, una nueva unificación de acciones, valores y normas, desde un solo centro discursivo legitimador (laico o no), es decir, la emergencia de algún nuevo tipo de fundamentalismo o integrismo. Como se sabe, la ciencia y la moral modernas pretenden sujetarse a los ideales de una imparcialidad y objetividad que vienen aseguradas según sus propios criterios internos. Mediante diferenciación algunos componentes estructurales del mundo de la vida, que se presentaban unidos en y para una conciencia colectiva, terminan separándose, pues cultura, sociedad y personalidad formaban una unidad estrecha. Como lo afirma Habermas:

Cada cual tiene entonces sus variables de legitimidad discursiva. Desplazamiento del saber sacro por un saber basado en razones y especializado; separación de legalidad y moralidad; universalización del derecho y la moral. Difusión del individualismo vía pretensiones de autonomía y autorrealización. (1987:4)

Elevada a conciencia, esta situación - es decir, las consecuencias negativas de los distintos fundamentalismos—, lleva a justificar la necesidad de la tolerancia y, después, a poner en el centro, como un sello de las sociedades modernas y más o menos liberales,

1 Por supuesto, esto no implica decir que este proceso se ha vivido —o resultado — de la misma forma en el Occidente europeo o noramericano que en nuestro continente. 
la existencia de un nuevo politeísmo axiológico. Sin un centro unificador y legitimador consagrado colectivamente de acciones y sistemas, lo que termina poniéndose de relieve es lo que Rawls (1979, en especial capítulo 1) llamará 'el hecho del pluralismo', como un dato esencial de las formas de vida actuales. Esto es, un reconocimiento de la capacidad de cada persona para decidir en conciencia y normar su propia existencia a partir de sí mismo (en un contexto determinado, por cierto). No parece haber ya otro sistema parcial que pueda reemplazar a la religión en su función articuladora. Rápidamente, entonces, se allegan preguntas importantes: desde dónde podrá construir su coherencia y deber ser la sociedad moderna? ¿Cómo llegar a criterios comunes para evaluar y validar lo justo o injusto, bueno o malo, deseable o no en la práctica social y las instituciones? La adecuada comprensión de esta situación es uno de los rasgos que marca el actual debate sobre la ética a distintos niveles en nuestras sociedades. No es intención nuestra ni trazar esta situación ni describir o evaluar aquí ese debate en curso.

Lo dicho más arriba tiene como objeto mostrar que la articulación actual entre legalidad y legitimidad, derecho, moral y política no es un movimiento autoevidente ni sencillo. Por una parte, requiere poner una fundamentabilidad moral-política formalizada (procedimentalizada); ${ }^{2}$ por la otra, un derecho que — aunque positivizado — conserve su apertura hacia el entorno, en un viaje de ida y vuelta. Por eso, la posición habermasiana es una que parte tomando razón de los procesos de autonomización y diferenciación modernos a distintos niveles, pero que no va hasta caducar toda posibilidad de abrir esclusas mutuas entre ellos — desde la crítica y reconsideración del suelo vital de la existencia común o mundo de la vida, en el cual nos movemos desde siempre en tanto sujetos hablantes insertos en determinados contextos históricos y socioculturales predados. Por esa condición nuestra de sujetos hablantes desde comunidades de comunicación, es que se cuela siempre una posible evaluación ético/moral de lo dado.

Como se deja ver, por ejemplo, en su relectura del fenómeno del derecho, la reflexión habermasiana es una en la cual, entre otros motivos, se teje una búsqueda constante por conservar abierta - a distintos niveles_-, la tensión entre el momento fáctico de la realidad social, política, económica o jurídica, y su momento normativo, referido a la justificación esgrimida en la acción por los poderes o los mismos sujetos — que forman parte de ella. Esta tensión —elevada a nivel reflexivo- resulta una de las claves de lectura plausible de los trabajos habermasianos, sea de talante sociológico, filosófico o político. De ahí la relevancia teórica y práctica de la discusión sobre el sentido de la crisis de lo moderno y de la interrogante sobre si aquella crisis cancela de manera definitiva el ideario emancipador, de libertades, autorrealización, autonomía y profundización de la democracia.

2 Y que, en todo caso, si se evalúa como pertinente y necesario reponer temas de felicidad y bien común, por ejemplo, se lo haga de un modo ya debilitado en cuanto a su ontologización, y que puedan, más bien, arrancar de la propia experiencia del individuo inserto en una determinada comunidad de comunicación y contexto sociocultural. 
Vol. XXI / № 1 / 2007 / 83-110

Darle la espalda a los propios acontecimientos y formas de un mundo cada vez más complejo lleva a un utopismo sin destino. Sin embargo, la actitud contraria condena al ser humano a un cierre, a una clausura respecto a las posibilidades de comprender y modificar la facticización de sus propias creaciones históricas, convirtiéndolo en apéndice desencantado de un destino inexplicable e inexpiable. Por ello, ni el sociologismo - que pone entre paréntesis la potencia reformadora de la acción comunicativa - ni el irracionalismo de una razón que no conecta con los presupuestos de sus condiciones de posibilidad y de análisis, se revelan conducentes para dar cuenta del estado de cosas actual. Quizás, en esta manera de asir ambos cabos - la dialéctica entre instituido e institución, proceso y resultante- puede verse una vía propia para retomar las sendas abiertas y perdidas del marxismo crítico, del weberianismo, de autores como Lukacs o K. Korsch, e incluso de filósofos como un Heidegger, entre otros, pero sin sus aporías insalvables. ${ }^{3}$ De lo que se trata entonces es de recuperar o mantener de modo legítimo, es decir racional, la dimensión normativa en el campo de la acción política, jurídica, social o de las pretensiones ético/morales. Mantenerla y/o reconstruirla frente a la dialéctica modernidad/modernización que, historizada, redefine y complejiza las relaciones entre facticidad y validez.

Hemos señalado que para Habermas la modernidad, en cuanto proceso de racionalización de los mundos de vida, se reafirma como un fenómeno muy complejo, leído desde las distinciones realizadas por Hegel, Marx, Weber o Lukacs, entre otros. En el proceso de racionalización social que ese fenómeno comporta, se van debilitando los aspectos portadores de emancipación y reconciliación, y aquellos más ligados a elementos represivos y a causas de división (cf. Habermas 1989). Aquí, racionalización implicará, al mismo tiempo, diferenciación y condensación, urdiendo así un tejido de hilos intersubjetivos que reúnen los elementos cada vez más diferenciados de la cultura, la sociedad y la persona. Con esta situación a la vista, Habermas es consciente de las dificultades que tiene el eventual potencial de una intersubjetividad comunicativamente establecida, más aun, frente a un mundo de la vida crecientemente racionalizado bajo la impronta de una socialización fuertemente individualizante. De allí entonces que, en medio de esta situación, no se vea como una tarea sencilla determinar y reconstruir los contenidos normativos de la modernidad y, de ese modo, salvaguardarlos no sólo del vendaval racionalizador y objetivador, sino también de aquellas interpretaciones que lo leen como un camino inviable debido al supuesto nuevo paisaje de un mundo totalmente administrado, sin dejar espacio para el contenido ambivalente de la modernidad social y cultural:

las diferencias y contrastes (ilustración/manipulación, fuerzas de producción/fuerzas de destrucción, efectos garantizadores de la libertad/efectos

3 Véase del autor sus Perfiles filosófico-politicos (1986) o las entrevistas consignadas en sus Escritos políticos (1985). 
destructores de la libertad) están ahora tan socavados, e incluso demolidos, que la crítica, en el chato y descolorido paisaje de un mundo totalmente administrado, totalmente sometido a cálculo, integralmente transido por relaciones de poder, ya no puede distinguir contrastes, matices o tonalidades ambivalentes. (Habermas 1993:400)

Por ello mismo, entonces, no es fácil la tarea de rehabilitar una idea de razón como praxis comunicativa desde la cual puedan salvaguardarse y proyectarse — $\sin$ ir a dar a nuevas totalizaciones, desde la crítica radical de la razón y/o la teoría de sistemas- los contenidos normativos de la modernidad (autorrealización, autodeterminación, autoconciencia).

En Habermas, ese espacio o esa brecha de normatividad no tiene que seguir todas las aguas del trascendentalismo, del idealismo o de algún irracionalismo. Tampoco debe anclarse en el supuesto de alguna ley moral interna, confiarse en la acción de un espíritu absoluto o en la acción salvadora de un macrosujeto. Tampoco, por cierto, debe abandonarse a la forma luhmanniana de sancionar una reconciliación imposible y a la vez cumplida mediante la dialéctica entre sistema y entorno. El desafío de Habermas es extraer esas posibilidades normativas desde una inmanencia abierta. La opción por este camino le impondrá también sus restricciones, lo cual muestra su desconfianza en las soluciones neofundamentalistas —en cualesquiera de sus versiones-o aquellas de acento neoaristotélico. ${ }^{4}$

No será entonces una normatividad sustancialista la que se intentará recuperar — sea en el plano de la acción social como en el de lo ético/moral-, asunto por el cual Habermas no ha dejado de recibir críticas hasta el día de hoy. Ese inmanentismo abierto paga el precio de su procedimentalidad, de su formalidad, centrada en las condiciones de validación, de justificación de la acción, de las prácticas colectivas, de las decisiones mancomunadas y las normas jurídicas, políticas y sociales en el espacio público. ${ }^{5}$

¿Qué deja entre paréntesis o, más bien, a disposición de la capacidad de los propios interesados en el plano de la normatividad ética? Las definiciones fuertes, las imágenes con contenido de lo que deba hacerse, de la finalidad o el bien hacia el que habría de orientar el actuar de cada cual, según sus creencias o cosmovisiones (cf. Habermas 2000). Se mueve como en un desfiladero: a un lado, las aguas de la facticidad instituida en lo social-moral, el dato de los hábitos, las costumbres, los modos establecidos de la acción y

4 Por ejemplo, véase la crítica al neoaristotelismo en la versión de Mac Intyre, centrada en la noción de 'virtud' que realiza Habermas (1985).

5 Las críticas recogen los vacíos que tendría el enfoque habermasiano (y apeliano) en relación, por ejemplo, a las reivindicaciones de género, a los temas del contexto comunitario o a la búsqueda de la felicidad. Según sus detractores, el excesivo racionalismo y abstracción de Habermas prefiguran un sujeto desencarnado, descontextualizado, asexuado. Véase Benhabib (2006). 
sus criterios dados ya por ciertos; del otro, aquellas que poseen ya un acceso privilegiado al suelo de las definiciones esenciales de lo que hay que hacer, de los fines y los bienes que rigen la existencia. En un lado, una normatividad ahogada en su facticización; en el otro, una definición a priori, suprahistórica o hiperesencialista de felicidad, bien o belleza. El camino habermasiano se revela modesto. ${ }^{6}$ Como si el autor pusiera mucho cuidado en que esa recuperación de la dimensión normativa no termine por negarse a sí misma. Ello sucedería si ese intento de recuperación o salvaguarda de lo normativo se realizara como si en el último siglo nada hubiera pasado en el terreno de la reflexión filosófica, política, ética, social. Como si pudiera recrearse una visión de mundo, de la razón y la racionalidad que no tomase en cuenta la autonomización de esferas de valor propias de la época moderna (verdad, bien y belleza), las dificultades para una reposición de la metafísica o de algún tipo de idealismo ontológico:

quiero insistir [...] en que la razón comunicativa — pese a su carácter puramente procedimental, descargado de toda hipoteca religiosa y metafísica-, queda directamente entretejida con el proceso de la vida social merced al hecho de que los actos de entendimiento adoptan el papel de un mecanismo de coordinación de la acción. El tejido de acciones comunicativas se alimenta de los recursos que a su disposición pone el mundo de la vida y constituye a la vez el medio a través del cual se reproducen las formas de vida concreta. De ahí que la teoría de la acción comunicativa pueda reconstruir (con independencia de toda premisa de filosofía de la conciencia) el concepto hegeliano de 'totalidad ética', mediante una 'implacable inmanencia'. (Habermas 1993:375) ${ }^{7}$

Si no hay algo pre-dado en la interioridad — como ley natural o como precepto tradicional incondicionado- y lo que hay, en este ámbito de lo práctico, es de algún modo producido en la interacción histórico-social, entonces el enfoque ético-normativo tendrá un fuerte énfasis reconstructivo. No podemos ya sostener razones convincentes respecto a opciones valórico/normativas desde la autoridad de tradiciones incuestionadas. Dicho de otro modo, se trata de encontrar en una relectura del mundo humano social mismo, las fuentes de la obligación ético/moral, y ya no en una razón subjetiva desligada o apriorizada de todo contexto histórico/cultural o, a contrario sensu, en una trascendencia puesta como indiscutible. De allí la presencia fuerte del principio de discusión, de la intersubjetividad argumentativa, del lenguaje como posibilitador y 'abridor' hacia esta

6 Este es uno de los puntos que se discuten en torno a la espinuda cuestión de los fueros del contexto y los mundos de vida y los de la racionalidad, en el establecimiento de criterios de normatividad y validez en el plano ético/moral o ético-político.

7 Lo cual, claro está, no implicará aquí un cierre dogmático y a priori de la razón comunicativa hacia una eventual dimensión de trascendencia de la experiencia humana. 
dimensión, y del especial énfasis —en la tradición kantiana - en sus condiciones de posibilidad, es decir, en su legitimidad y universabilidad. Es por el lenguaje y por lo que en él se pone en movimiento — siempre desde la interacción o intersubjetividad—, que podemos aún volver sobre nuestro propio mundo externo e interno, sobre nuestras propias obras y discursos, sobre las normas dadas, de una manera no ingenua, sino crítica, de modo de no quedar condenados a la clausura en las lógicas de los subsistemas o a la huida hacia una interioridad sin contornos.

La posibilidad de esta nueva mirada conformadora del espacio ético/moral no va de suyo. Ha implicado que Habermas — de la mano de la influencia de K.O. Apel, del pragmatismo filosófico americano, de la filosofía del lenguaje, de G.H. Mead- asuma (sin negar el impulso emancipatorio presente en el marxismo crítico de Frankfurt), una perspectiva poskantiana, posweberiana, bajo la influencia del llamado 'giro lingüístico' y una hermenéutica crítica. La asunción propia y ecléctica de esas distintas ópticas le han posibilitado ver y poner al lenguaje como articulador y posibilitador de una razón éticodiscursiva y comunicativa (cf. Giddens et al., Bernstein 1988).

Ahora bien, podría inquirirse sobre cuándo a Habermas le interesó esta aproximación al fenómeno ético/moral — desde esos puentes que establece siempre entre filosofía y ciencias sociales-, si sus escritos al respecto datan de los años ochenta en adelante. Pues la verdad es que para él los asuntos éticos conectan ya con sus trabajos de fines de los sesenta y comienzos de los setenta. En particular, los referidos a los problemas de legitimación y crisis más o menos periódicas derivadas del capitalismo tardío, producto de las erosiones que generan en los mundos de vida las tendencias mercantilizadoras, formal/cientifizantes o instrumentalizantes. Allí Habermas desarrolla el tema de los intereses generalizables que están de algún modo reprimidos, amenazados, y que ponen en cuestión las vías de legitimación en cuanto "las cuestiones prácticas no son veritativas, y los valores se vuelven irracionales" (Habermas 1989:101). ${ }^{8}$

Los temas éticos quedan entre paréntesis en su teoría de la acción comunicativa (TAC) en cuanto allí el esfuerzo se dirige más bien al abordaje y esclarecimiento de las patologías sociales mediante su idea de sociedad articulada en dos planos: sistema y mundo de la vida. Para esta tarea Habermas tiene la impresión de que la teoría moral no le ha sido útil. Más allá o más acá de la TAC, lo que sí se va imponiendo en el autor es la conciencia de un malestar con la modernidad, reflejado a través de esas patologías. Este malestar alcanza también, cómo no, el ámbito ético/moral de la vida en común, expresado en la pérdida de referentes comunes, en la incapacidad creciente del sistema cultural para proveer motivaciones y sentido a la acción personal y colectiva, lo que va más allá de planteos estratégico-utilitaristas. Por otro lado, esta situación de complejidad

$8 \quad$ Para el tema de las cuestiones veritativas y los intereses generalizables, véase Habermas (1989:124 y ss.). 
Vol. XXI / № 1 / 2007 / 83-110

crísica del humano se vislumbra también en el predominio de visiones de la sociedad deterministas o evolutivo-positivistas. Ambas situaciones muestran el cuestionamiento en que vive la ética pública y la condición humana misma.

Los motivos de inquietud ética en el presente se ligan entonces a una situación donde no tenemos más homogeneidad cultural y se debilitan los lazos orgánicos a los cuales anclar creencias y convicciones, donde, por lo mismo, las instituciones de carácter democrático se debilitan a tal punto de trocarse en una democracia de espectadores. Esta situación queda bien graficada cuando Habermas afirma en Facticidad y validez que

los sujetos que constituyen en cada caso mundos propios (particulares) o que comparten intersubjetivamente mundos comunes, han quedado en adelante sin lugar; al mismo tiempo, todas las operaciones de integración intencionales, puestas en acción por la conciencia de los propios actores, pierden su legitimidad. Todas las huellas hermenéuticas que permitirían a una teoría interna de la acción, basada en la visión que los actores tienen de ellos mismos, acceder a la realidad social, quedan ahora borradas. (Habermas 1998:111)

Por ello, no es tarea fácil redefinir el espacio y ámbito para una ética pública bajo esta situación. ¿¿Cuál es el problema? Que en un mundo desencantado y plural no es evidente encontrar lugares desde donde replantear, de manera adecuada, los destinos de una razón ética pública. No lo parece, al menos, el volverse hacia un tradicionalismo o darse a las aguas posmodernistas. De ahí entonces su propuesta de una ética discursiva —algunos de cuyos rasgos plantearemos más adelante. Habermas toma conciencia del pluralismo y se sigue preguntando en torno al lugar desde el cual extraer un núcleo universalista para los enunciados morales. Se trata de ir más allá (no retrotraer la mirada) del realce metafísico de un Aristóteles, por ejemplo, de una visión de la polis como objeto y medio de vida ejemplar en la cual los humanos — no esclavos ni bárbaros-, pueden implementar el telos de una vida buena. En la modernidad, o desde ella, la filosofía ya no puede por sí y ante sí juzgar la pluralidad y multiplicidad de proyectos personales y formas de vida desde un solo punto de vista. Tanto el telos de la vida personal como el modo de vivir quedan ahora para ser enjuiciados desde cada participante; $y$, al parecer, lo único que podría convencer a todos se reduce al procedimiento de formación de la voluntad común.

Vistas así las cosas, para Habermas queda entonces averiguar la vía de la inmanencia lingüístico-comunicativa, presente y obrante siempre, desde ya en los mundos de vida (Lebenswelt) de los que participan cada sujeto en cada sociedad, como espacio (situado) desde el cual se abre una brecha para que la subjetividad pueda retener, reinterpretar o reformular sus aspiraciones valórico-normativas, sin quedar restringidos a las tradiciones reinantes, o sujetos a los contextos morales más o menos institucionalizados/funcionalizados. La posición del lenguaje le permite esa inmanencia sin que, por tanto, los 
criterios normativos tengan que venir dados en exclusiva desde fuera de los sujetos mismos o desde una tour de force de la razón misma. De esto se trata justamente acá. Esta dirección se muestra para Habermas — y hay que decir que en sentido lato también para Apel (1986) — , como la única vía válida que permite afrontar la presencia creciente en la esfera cultural de un politeísmo axiológico, del pluralismo y del escepticismo; todos ellos, en buena medida, resaltados por un proceso de racionalización en que adquiere presencia dominante su expresión estratégico-instrumental. ${ }^{9}$ La presencia del escepticismo es problemática, porque termina complementándose con aquellas posiciones provenientes del cientismo (sea en el ámbito de las ciencias duras o de la misma economía) o del irracionalismo que niegan que los asuntos ético/normativos puedan abordarse y dilucidarse mediante un debate fundamentable de manera argumentada y participada. A fin de cuentas, el escéptico terminaría cayendo en una contradicción performativa, que invalidaría su actitud de imposibilidad y abstención.

Ahora bien, el rol central del lenguaje y su potencialidad prescriptiva lo descubrimos mediante el examen de su uso (pragmático), en su propio funcionamiento recíproco, en el que se revela una orientación y coacción al entendimiento entre aquellos que forman parte de las distintas comunidades de comunicación en juego. El humano en su accionar está obligado, por decirlo así, a intentar entenderse mutuamente en la medida en que las relaciones interhumanas funcionan con un permanente recurso a la interpretación (de gestos, actos, palabras), en tanto los sentidos y significados implicados en ellas no son autoevidentes. Este rol central se basa en la idea de Habermas de que el lenguaje posee un telos propio, interno: el estar orientado al entendimiento (Verständigung). Esta afirmación se acompaña a su vez de algunas otras a tener en cuenta: a) en la idea de mutuo entendimiento subyace otra idea que nos dice que esa búsqueda tiene como orientación acuerdos libres no coactivos, es decir, no sometidos al dominio y poder vigentes, con lo cual se establece un potencial que puede hacer de contrastante de la dominación; b) hablar de entendimiento mutuo implica tener una noción más amplia de racionalidad. El objeto de su estrategia es no quedar endeudado con alguna trascendencia (religiosa, naturalizada o histórica). Se trata de que los criterios de validación a/de los eventuales acuerdos vehiculizados a través del mutuo entendimiento, provengan de su propio movimiento o expresión, como presupuestos ya en acto en los procesos de intercomunicación lingüística, por ejemplo, que sean inmanentes; c) hablar un lenguaje implica esgrimir, realizar ciertos actos de habla, un tipo de acción, para lo cual requerimos competencia

\footnotetext{
Para algunos, sin embargo, las formulaciones de la ética discursiva y el principio de discusión no alcanzan para torcerle la mano al cínico, es decir, para aquel que desde la partida se niega a ser parte de alguna comunidad de comunicación y respetar sus reglas de interacción. A pesar de lo que sostienen los detractores de la ética discursiva, el cínico se invalida a sí mismo en la conformación de los diálogos societales y, por ende, queda fuera de ellos. Es así, salvo que supongamos que el conjunto de la cultura y de la política de poder esté atravesado por el cinismo y que sea este entonces el principal 'adversario' a enfrentar en el plano ético/moral y político.
} 
Vol. XXI / № 1 / 2007 / 83-110

lingüística y comunicativa y, acorde a ello, seguir ciertas reglas para su cumplimiento, es decir, para que la interacción comunicativa pueda cumplirse.

Es por medio del uso del lenguaje, de lo que Searle llamó actos de habla, que se cuela un talante normativo implícito en el mismo acto de emitir un juicio, formular una petición, prometer, dar una opinión o realizar una evaluación. El ser humano se hace a sí mismo en su permanente interactuar con los otros, y por eso el lenguaje es aquí consustancialmente intersubjetividad, diálogo, capacidad de encuentro y desencuentro en - y desde- la acción comunicativa. Por cierto, esto no implica desechar sus institucionalizaciones, sus sedimentaciones y traspasos en cuanto a su carga de significaciones, ligadas a los distintos temas, comunidades y culturas donde se despliega.

En el transitar del yo pienso monológico al nosotros argumentamos se revelan entonces algunas condiciones que aparecen como presupuestos éticos sin los cuales el entendimiento y la intercomunicación serían imposibles. Esos presupuestos se revelan en el mundo de la vida cotidiana — constituida desde la acción comunicativa - como pretensiones de validez presentes en todo discurso o proceso argumentativo: a) sentido (inteligibilidad pública); b) veracidad (que el oyente le crea al hablante lo que expresa); c) verdad (respecto al contenido proposicional de lo dicho y su eventual consenso); d) corrección (que manifiesta la legitimidad del discurso como acción social de comunicación).

Pareciera que todo aquel que de manera seria desea participar en argumentaciones no puede sino aceptar implícitamente esos presupuestos pragmático-universales que poseen un claro contenido normativo. Esto, claramente no es sólo un asunto que compete a cada cual, esto es, si decide cumplir o no con esos implícitos a nivel personal; tiene que ver con el destino mismo de la propia convivencia. Si ello no fuera así, según Habermas

La violación de las pretensiones de verdad, rectitud y veracidad afecta al todo que el lazo de la razón transe. No existe ninguna posibilidad de huida, no existe ningún afuera para los pocos que están en la verdad y que se distinguirían de los muchos, de los que permanecen atrapados en la tiniebla de la obcecación, como el día se distingue de la noche. Una violación de las estructuras de la convivencia racional, estructuras que todos tienen que dar por supuestas, afecta a todos por igual. $(1993: 384)^{10}$

Por tanto, hay un suelo para los contenidos normativos en la ética y en su racionalidad propia que no viene desde fuera de los sujetos ni es producto unilateral de alguna creación. Instalado en lo que revela el análisis de la inmanencia del lenguaje y del hecho argumentativo, el descubrimiento del rol de la discursividad y de cómo a través de ella

10 La importancia social y política de estas afirmaciones relativas al rol del conflicto y a las formas de su abordaje no resultan lejanas para la experiencia sociopolítica nacional y latinoamericana. 
pasa el accionar de la razón —ahora como razón comunicativa—, termina redefiniendo al humano-sujeto en cuanto poseedor de capacidad lingüística y también de competencia comunicativa. Tenemos las bases, entonces, para la formulación de una ética de talante discursivo o, dicho de otra manera, para la recuperación de los fueros de una racionalidad que no se limita a su expresión instrumental o estratégica, o sistémica, sino que es capaz de obrar — de manera compartible y con sentido—, en el nivel de lo éticomoral, esto es, en un plano normativo.

En esta reinvención discursivo-dialógico contemporánea de la ética se trata, vía el descubrimiento de la radical comunicabilidad de la razón, de ir más allá del individualismo y sus bases (solipsismo, positivismo, irracionalismo), y de abrir un camino legítimo para el accionar de la razón y el acuerdo en el espacio ético/moral. El devenir de la modernización consagra un conjunto de separaciones/esciciones en apariencia irreconciliables: público-privado, teoría-praxis, conocimiento-decisión, hechos y valores, etc. No sólo eso. Esa modernización pretende cancelar las posibilidades mismas de plantearse una racionalidad ética al ponerla en un paréntesis flanqueado, a un lado, por una actitud cientificista y, al otro, por una irracionalista. Ambas aristas hacen imposible un espacio de expresión propia para una razón práctica. Por eso, esta situación impide la posibilidad de una ética pública validable más allá de intereses estratégicos o inmediatos. Su terreno se vuelve el escepticismo o, incluso, el nihilismo. Por tanto, alienta una política y una institucionalidad económica, política o social inerme ante la colonización paulatina de criterios instrumentales o decisionistas. La ética y la moral son asuntos de cada quien por separado y por su cuenta, pero no pueden dilucidarse en el entramado social de la vida en común o de las instituciones. La ética del discurso pretende entonces abrir nuevamente fueros de legitimidad para una razón práctica e histórica, capaz de habérselas de otra manera, claro está, con los dilemas de la acción del presente y sus eventuales discernimientos. En otras palabras, pretende hacerle un espacio legítimo a lo normativo, más allá de su reducción en la visión empírico-analítica o su expresión en las agendas irracionalistas.

La mirada de la ética desde la discursividad se plantea entonces como crítica de las limitantes sociohistóricas de la razón moderna pero, a su vez, busca rescatar y reinterpretar sus ejes normativos más relevantes (libertad, igualdad, fraternidad), en función de las nuevas realidades abiertas desde el pensar filosófico, como desde la propia realidad histórica. Para ello ofrece más bien una comprensión mínima de la ética: por una parte, se muestra como universalista, deontológica, cognitivista, formalista y posconvencional; por la otra, deja en segundo plano el tratamiento y discernimiento de los temas relacionados con el bien o la felicidad. Una vez que nos cercioramos de la imposibilidad de resolver, desde lo alto y de una vez para siempre, asuntos relacionados con la justicia, el bien o la felicidad, para cada uno o para el todo, el problema que se plantea es cómo decidir cuestiones normativas: ¿por imposición, por violencia directa, por el poder de los intereses? Claramente mediante ninguno de estos modos, sino a través del ejercicio de convicciones sin violencia, obtenidas sobre la base de un acuerdo racionalmente motivado. 
El carácter posmetafísico de la propuesta de Habermas se vierte en algunos rasgos que hacen a la ética reconocible y que, por cierto, hasta hoy no han dejado de suscitar dudas y cuestionamientos. Revisemos algunos de sus rasgos. Primero, dijimos que la ética asume una óptica deontológica. Esto es, se trata de intentar configurar una racionalidad ética desde una reformulación del imperativo categórico kantiano. Lo importante es continuar el paso del 'yo argumento', monológico, al 'nosotros argumentamos', en una suerte de deontologismo dialógico. En este punto es relevante la aspiración al valor universal de las normas comunes, algo que puso de relieve de manera singular la reflexión kantiana. Kant lo señaló con fuerza debido justamente a que el rasgo de obligatoriedad de las normas no puede ya venir garantizado desde fuera de los participantes o desde lo alto, esto es, por autoridades exteriores al propio juicio de los involucrados. Entonces, si ello es así, el tema es diseñar aquellos procedimientos bajo los cuales puede cumplirse esa pretensión de obligatoriedad para más de uno. Pero esto no queda sólo aquí. A diferencia de la fórmula kantiana - aun enclavada en una idea de razón individual, abstracta y ahistórica-, las cuestiones ético/morales no pueden resolverse ya de manera individual, sino que demandan un esfuerzo cooperativo mancomunado. Este esfuerzo tiene como fundamento la idea habermasiana de acción y razón comunicativa. $\mathrm{O}$, como hemos dicho, su idea del lenguaje como radicalmente intersubjetivo:

No basta con que todos los individuos hagan esta reflexión, cada uno para sí mismo, y luego depositen su voto. Antes bien, lo necesario es una argumentación 'real' en la que participen de modo cooperativo los afectados. Únicamente un proceso de entendimiento intersubjetivo puede conducir a un acuerdo que sea de carácter reflexivo: sólo entonces pueden saber los participantes que se han convencido conjuntamente de algo. (Habermas 1985:87-88; cf. Habermas 1991a:101 y ss.)

No hay que olvidar que las necesidades se interpretan culturalmente y sus valores pertenecen a una tradición intersubjetivamente compartida. Cada sujeto es la última instancia moral, pero al mismo tiempo requiere de los otros con los cuales inevitablemente existe interactuando (Habermas 1985). Los enunciados morales exhiben una pretensión de validez universalizable que debe expresarse en la coparticipación argumentada de todos los eventualmente interesados. Al respecto, señalaba Adela Cortina que:

La voluntad racional, lo que 'todos podrían querer', sigue siendo el criterio para legitimar normas morales, pero desde el diálogo real y el cálculo de las consecuencias. Semejante norma nos dirá quiénes son 'todos' los incluidos en el concepto de voluntad racional que - frente a Kant— no serán todos los seres racionales $\mathrm{y}$ - frente a los convencionalistas - no serán todos los participantes 
de facto en el diálogo, sino todos los afectados por la entrada en vigor de la norma. (Cortina 1989:550)

Apel lo deja también establecido cuando enuncia una suerte de principio antropoético de la ética discursiva:

Todos los seres capaces de comunicación lingüística deben ser reconocidos como personas, puesto que en todas sus acciones y expresiones son interlocutores virtuales, y la justificación ilimitada del pensamiento no puede renunciar a ningún interlocutor y a ninguna de sus aportaciones virtuales a la discusión. (Apel 1985:400)

Con ello, subrayamos esa primera inflexión del imperativo categórico en uno dialógico-discursivo que considera desde el inicio la participación de todos los interlocutores en las decisiones valórico-normativas atingentes a su vida en común. Según Apel (1985), esta capacidad - que en su ejercicio convierte a los individuos en personas - se conecta con la legitimidad de las normas y valores en curso. Toda persona tiene en principio, en tanto competente comunicativamente hablando, derecho a participar de los discursos prácticos en los cuales se ven involucrados aspectos de su propia existencia social. Es decir, la formulación de un criterio tal preanuncia la correspondencia con una cierta forma de vida democrática, para que una ética de este tipo pueda expandirse o desarrollarse. Entre otras cosas, porque ello exige la consideración de cada sujeto como un ciudadano con derechos, que, en tanto tal, puede incorporar — y está capacitado para hacerlo— sus demandas y reivindicaciones, discursivamente hablando, en todas aquellas normativas que son atingentes a su vida como ciudadano social. Por tanto, desde ya, en su criterio de legitimación y/o búsqueda de validez en la óptica de una ética discursiva se intenta contrarrestar las visiones autoritaristas que saben de antemano lo que hay que hacer o decidir. ${ }^{11}$ Tiene, así, una implicancia política indirecta.

En la reformulación habermasiana, el lugar del imperativo categórico será entonces ocupado por el procedimiento de la argumentación moral. Esta posición será la antesala de la formulación que le dará Habermas y que será reconocida como principio D (o postulado ético discursivo), respeto a la validez y legitimidad de las normas, y que reza como sigue: "sólo pueden pretender validez aquellas normas que pudiesen contar con el asentimiento de todos los afectados como participantes en un discurso práctico" (1991a:101)..$^{12}$ Se trata aquí de la comprobación discursiva de las pretensiones de validez

11 A nombre de distintas 'instancias', claro está: el partido, la institución y su carisma, los poderes que da la imagen o el dinero, etc.

12 Cf. Habermas (1985:85 y ss, especialmente 117), donde el filósofo pone de relieve el lugar principal que ocupa el principio D. 
Vol. XXI / № 1 / 2007 / 83-110

que esgrimen o pueden esgrimir los participantes en un discurso práctico en torno a temas considerados de relevancia común:

el punto concreto de partida de un entendimiento normativo perturbado, y al cual se refieren siempre los discursos prácticos como antecedentes, lo determinan objetos y problemas que 'se prestan' a negociación [...] En su apertura, el discurso depende de que le estén 'dados' los contenidos contingentes. (1985:129)

Pero además de la forma a través de la cual se legitiman normas comunes, la ética discursiva, como ética poskantiana, se quiere también universalista. Una norma sólo será moral cuando esta sea universalizable, es decir, cuando sea el producto de la discusión y participación discursiva de los eventuales afectados por ella y que están en condiciones de producir acuerdos racionales respecto a los temas de debate, de un determinado talante y durabilidad. No se trata aquí de cualquier universalidad, o de un universalismo propuesto e impuesto desde arriba, sino de lo que puede llamarse la elaboración mancomunada de un universal pragmático. Se plantea entonces que el principio moral (U) posee una validez generalizable y no expresa sólo la intuición de una determinada cultura: "Una norma puede encontrar aceptación entre todos los participantes si (actualmente o no), todos pueden aceptar sin coacción las consecuencias [...] que surgen previsiblemente del cumplimiento universal de la norma, para satisfacer los intereses de cada individuo" (1985:129). En una versión más remozada de este mismo principio, Habermas sostenía que este rebajamiento del imperativo categórico en un principio de universalización se troca en una regla de argumentación que: "en el caso de normas válidas, los resultados y consecuencias laterales que, para la satisfacción de los intereses de cada uno, previsiblemente se sigan de la observancia general de la norma tienen que poder ser aceptados sin coacción alguna por todos" (Habermas 1991a:101-102). Tiene otro carácter al de enunciados como, por ejemplo: 'debes sonreír cuando saludas a otra persona'. "Sólo serán morales, entre otras razones, aquellas normas que no varían por razón de los espacios sociales y tiempos históricos" (Habermas 1985:86).

Los rasgos del universalismo y deontologismo se reafirman mutuamente si se formulan desde un cognitivismo ético. La ética discursiva se pretende a sí misma cognitivista porque sostiene la posibilidad de fundamentar con razones los enunciados normativos. En los asuntos prácticos que afectan nuestra vida en común, es factible dar o intentar dar razones, un fundamento — revisable y discutible - para nuestra acción y decisión, aunque no sea un fundamento último de ellas: "Kant no confunde la razón teórica y la razón práctica. Yo entiendo la validez normativa como una pretensión análoga a la de verdad. En este sentido hablamos también de una ética cognitivista. Ésta tiene que poder responder a la cuestión de cómo fundamentar los enunciados normativos" (Habermas 1991a:100-101). Cuando se consideran las normas desde la actitud realizativa de sus 
destinatarios, se presentan con una pretensión de validez análoga a la que exhiben los enunciados veritativos. Pero esto no implica sostener que aquellas se diseñen siguiendo los patrones de estas. Por de pronto, porque la sede de las pretensiones de validez normativa refieren a normas, es decir, a productos que trabajan con acciones morales y regulación de esas acciones. En cambio, los enunciados orientados por una pretensión a la verdad se orientan a la existencia de determinados estados de cosas. Además, el teórico moral coparticipa en discursos de fundamentación y/o aplicación de normas junto a los demás interesados en ello, y no en el establecimiento aislado de la veracidad de tales o cuales normas o principios. Para esto, claro está, tiene que distinguir entre validez y vigencia social de esas normas, entre el ethos en funciones en una sociedad y la evaluación o modificación de él que los participantes puedan querer y argumentar.

Otro rasgo al hilo de los elementos anteriores refiere al inevitable carácter formalista de la propuesta discursiva. Es decir, que la propuesta discursiva se interesa por ayudar a establecer las condiciones mediante las cuales una norma puede ser válida y/o legítima, y no tanto sobre cómo llevar una vida buena o feliz. Dicho de otra forma, representa una teoría moral ocupada en asuntos de justicia normativa. Para Habermas, que una norma sea justa o pueda redundar en interés de todos no significa sino que esa norma merece reconocimiento o es válida.

Aquí la justicia no es leída desde un determinado contenido material, sino como una dimensión de validez. A otro nivel estarían los principios que expresan un contenido específico, como por ejemplo cuando se refieren a la justicia distributiva. Refleja entonces esta dimensión el punto de vista desde el que las cuestiones morales pueden decidirse con imparcialidad; es el llamado punto de vista moral que asumen quienes participan en discursos prácticos. Participar en un discurso práctico representa el ejercicio de práctica pública de una recíproca asunción común de perspectivas. $\mathrm{O}$, una práctica en la que cada cual se ve obligado a adoptar el punto de vista del otro en función del examen de las reglas aceptables, para él y para los demás involucrados. Las éticas formalistas escogen una regla que declara cómo puede considerarse algo (como correcto) desde el punto de vista moral. Así, John Rawls (1979) escoge la 'posición original' y G.H. Mead (1968) recomienda una 'asunción ideal de rol'. Por nuestra parte, la ética del discurso ofrece el discurso práctico como

un exigente modo de formación argumentativa de una voluntad común que (al igual que la 'posición original' de Rawls) tiene por fin garantizar, merced sólo a presupuestos universales de la comunicación, la rectitud (o fairness) de cada uno de los acuerdos normativos que pueden establecerse en esas condiciones. (Habermas 1991b:104)

A través del discurso práctico es posible dirimir las cuestiones morales con la sola fuerza del mejor argumento y, además, obligar a todos los participantes a una simultánea 
Vol. XXI / № 1 / 2007 / 83-110

asunción ideal de rol (exige de todos ponerse empáticamente en el lugar de cada cual, olvidándose de sí mismos) (Habermas 1991a) que en la ética discursiva no es ya algo particular y privado, como en Mead, sino algo público, practicado intersubjetivamente por todos.

Los rasgos de universalidad, formalismo, cognitivismo y universalismo se acomodan bien, a su vez, a un modelo de ética posconvencional — y, claro, posmetafísico-, según la clasificación de L. Kohlberg (1992). Esto no implica desconsiderar los otros niveles en los que se refleja la ciencia moral y su evolución, sólo que acá está en juego — de manera acentuada - el ejercicio de reflexividad sobre el mundo social que se comparte y sobre los valores y normas en él transmitidos o predominantes. Por cierto, no es necesario que para la cotidiana toma de decisiones en este ámbito tenga cada cual que colocarse en el estadio posconvencional, pero sí lo es cuando se trata de autoesclarecerse mutuamente sobre los principios adecuados de acción, tanto para uno como para otros, referidos a determinados campos de actuación y/o regulación del vivir juntos, o cuando hay que establecer o restablecer determinados principios o normas orientadoras para las instituciones.

En una actitud posconvencional podemos revisar la eventual validez de principios o normas ya establecidos o, a partir de ellos, participar en discursos prácticos — públicos- con el objeto de instaurar nuevos principios o normativas más adecuados desde un punto de vista universalizable, es decir, de uno en el cual todos los afectados puedan verse como coparticipantes en su validación. En principio, lo único que exigiría esta etapa es la capacidad de reflexión y de ponerse en el lugar del otro para el abordaje de situaciones complejas o conflictivas:

también la ética discursiva, como otras ciencias reconstructivas, descansa en definitiva en reconstrucciones hipotéticas para las que hemos de buscar confirmaciones plausibles [...] Como tal confirmación cabe interpretar la teoría del desarrollo de la conciencia moral elaborada por L. Kohlberg y sus colaboradores. [...] El punto normativo de referencia de la vía evolutiva empíricamente analizada está constituida por una moral orientada en función de los principios: en ello puede reconocerse la ética discursiva en sus rasgos esenciales. (1985:137)

Ciertamente, esto no implica que la consideración kohlbergiana referida a los estadios evolutivos de la conciencia moral, no tenga o presente problemas. Entre otras cuestiones, se ha dicho que en verdad sólo una parte menor de la población adulta se mueve más bien a niveles convencionales (cuando no preconvencionales) de conciencia moral. Ello, cuando al mismo tiempo buena parte de nuestras instituciones políticas, sociales o jurídicas, se mueven en una lógica posconvencional. Un ejemplo de esta situación es 
justamente el derecho moderno, el cual — a pesar del nivel convencional de muchos ciudadanos - se mueve y cristaliza estructuras posconvencionales de conciencia moral. Por otra parte, también puede discutirse acerca de si las investigaciones sobre la conformación evolutiva de una conciencia moral dada, situada, realmente sigue esos pasos. Carol Gilligan (1994), ${ }^{13}$ por ejemplo, ha puesto en el tapete este tema, en función de reivindicar la singularidad de la psicología femenina en el terreno de la conciencia moral.

Los planteamientos de una ética discursiva se mueven a nivel ético/filosófico, es decir, a nivel de sus fundamentos racionales. Pero, tanto Habermas como Apel están conscientes de que ello no es suficiente. En el caso de Apel (1991), habla de una parte B de la ética discursiva que estaría orientada por una ética de responsabilidad posweberiana, la cual tiende a reconocer a todo humano como miembro de la comunidad de comunicación a dos niveles: la comunidad real, histórica, imperfecta, y la ideal, anticipada contrafácticamente en toda argumentación con sentido. Esto significa que la comunidad real de comunicación, en la que estamos siempre ya ubicados, anticipa el ideario de una comunidad libre de dominación, donde la discusión, acuerdos y consensos no están sólo mediados por intereses particulares, instrumentales o estratégicos o por el afán manipulatorio. Con todo, hay que decirlo, no se trata en esto de generar una nueva utopía concreta, sino más bien de verla — la comunidad ideal—, como una suerte de idea reguladora.

En lo que se refiere a Habermas, prefiere no seguir en esto la ruta de su colega Apel y más bien desarrolla argumentaciones en las cuales complementa la preocupación por cuestiones de justicia (igualdad de derechos y respeto por cada cual), con la solidaridad, como virtud y valor presente en los mundos de vida y a través de la cual se exige preocupación y solicitud por el próximo a partir de las diferentes formas de vida concreta. Aquí las intuiciones morales — que pertenecen a los mundos de vida y que hay que preservar- están presentes y actúan como dispositivos de protección para los humanos entre sí, los vivientes más vulnerables física y espiritualmente en lo que a su identidad se refiere:

'Morales' voy a llamar a todas las intuiciones que nos informan acerca del mejor modo de comportarnos para contrarrestar mediante la consideración y el respeto la extrema vulnerabilidad de las personas. Pues, desde un punto de vista antropológico, la moral puede entenderse como un mecanismo protector que sirve de compensación a la vulnerabilidad estructuralmente inscrita en las

13 Véase la discusión que Habermas (2000) realiza respecto al nivel 6 sobre justicia y solidaridad, y también sus reflexiones en torno al neoaristotelismo y la posición kohlbergiana. La indagación de la marcha de la conciencia moral en nuestras sociedades modernizadas se revela también una tarea difícil. Cf. al respecto Salvat (2000: supra nota 3). En la misma temática, cf. Benhabib (2006:supra nota 11). 
formas de vida socioculturales. Vulnerables en este sentido y, por tanto, moralmente necesitados de atención y consideración son los seres que sólo pueden individuarse por vía de socialización. (1991b:106)

Las éticas de la compasión se percataron de esta profunda vulnerabilidad de las personas y de su necesidad de atención y consideración recíprocas, planteando la benevolencia como forma de acceder al quebranto del otro. En efecto, todas las éticas han girado en torno a la justicia, la solidaridad y el bien común. Todas han tratado de responder a la necesidad de trato igual para con todos y de protección para las relaciones intersubjetivas a partir de las que constituimos nuestra identidad. A cada uno de estos aspectos responden la justicia y la solidaridad, respectivamente. Asimismo, a cada una de estas intuiciones morales ha correspondido, a lo largo de la historia de la ética, ocupar el lugar de preferencia en éticas del deber, centradas en cuestiones de justicia o en éticas de los bienes, especializadas en el bien común.

Pero ya Hegel se percató de que yerra la unidad del fenómeno moral básico cuando se aíslan ambos aspectos oponiendo un principio a otro. El concepto de eticidad de Hegel parte, por tanto, de una crítica a dos unilateralizaciones que resultan simétricas. Hegel se vuelve contra el universalismo abstracto de la justicia tal como viene expresado en los planteamientos individualistas de la Edad Moderna, así en el derecho natural racional como en la ética kantiana; pero con la misma decisión rechaza el particularismo concreto; del bien común tal como se expresa en la ética de la polis de Aristóteles o en la ética tomista de los bienes. La ética del discurso hace suya esta intención básica de Hegel para desempeñarla con medios kantianos. (1991b:109)

Por último, es útil señalar también que la ética discursiva apoya de manera indirecta las decisiones y acciones de los participantes en discursos prácticos. Es decir, no le señala a cada cual qué debe decidir, o cómo debe actuar frente a situaciones complejas o conflictivas. Procede de esta forma porque reconoce a cada cual su capacidad y competencia para participar en las discusiones y decisiones que dicen relación con problemas, decisiones y normas que les afectan. En este sentido la ética discursiva se plantea plenamente moderna. Al mismo tiempo, Habermas en particular, subraya un papel más bien modesto para la filosofía en este plano. No pueden ya los filósofos por sí y ante sí pensar y decidir por los individuos o las comunidades que enfrentan tales o cuales problemas o situaciones. Como Habermas lo reconoce, la filosofía no exime a nadie — ni siquiera a los propios filósofos- de hacerse responsable de los problemas de su tiempo. 


\section{De la ética del discurso al principio de discusión, la política y el derecho: una nota}

La ética del discurso tiene la particularidad de ser una ética en construcción, una en la cual el esfuerzo se concentra en los argumentos que hacen posibles una normatividad a la altura de los tiempos. Transitamos aquí desde una ética que nos prescribe normas y mandatos hacia una en la cual la determinación de las normas y su validez pasa a ser un asunto que compete a una discusión libre, argumentada y consensual. Es por esto que aparece como modesta en sus pretensiones. Se limita a revisar el momento de la justicia en la producción y legitimación de normas que competen al vivir en común. Sin embargo, Habermas es consciente de que la justicia normativa no es suficiente en la marcha de los asuntos comunes, por eso cada vez más incorpora la importancia del principio solidaridad. Los acuerdos mediante discusión participativa no pueden darse sin la existencia de una cierta solidaridad, es decir, sin el sentimiento de pertenencia a una comunidad ideal de comunicación, y sin la certidumbre de una copertenencia fraternal en un contexto de vida en común:

La justicia y la solidaridad son las dos caras de una misma moneda, porque el discurso práctico, por un lado, deja la aceptación o rechazo de las propuestas de que se trate en manos de cada uno, y en este sentido da razón de la comprensión individualista de la igualdad de derechos; por el otro, en el discurso permanece intacto ese lazo social que empuja a todos los participantes en la argumentación a tornarse conscientes de su pertenencia a una comunidad ilimitada de comunicación. (Habermas 1991d:198-199)

Sin la empatía solidaria de cada cual en función de las posiciones esgrimidas por los otros, sería difícil que cada cual se comprometiese en el camino de una solución que pueda llevar al consenso. Justamente, en la perspectiva de cierta fraternidad y empatía solidaria es que puede rehabilitarse el sentido mismo de la justicia. Por una parte, no nos es posible renunciar a la justicia porque ella refiere a la igualdad de libertades y derechos de personas que no pueden delegar ya en otro su representación; por la otra, tampoco podemos renunciar a la solidaridad, en cuanto refiere al bien de camaradas hermanados en una forma de vida compartida intersubjetivamente y, por ello, necesitada de protección y conservación de la integridad de esa forma de vida. Una ética normativa, como la ética del discurso, no puede proteger la justicia prescindiendo de la solidaridad; ${ }^{14}$ no

14 Sobre el tema de la solidaridad Habermas ha trabado una discusión con Richard Rorty (1991), para el cual es un recurso de integración importante, pero ligado a la contingencia de un contextualismo pragmático (en el sentido lingüístico) y posmoderno, y no a una suerte de condensación abstracta de una experiencia común (patriotismo solidario, por ejemplo). Véase Rorty (1991, especialmente capítulo 3). Para una consideración crítica de Rorty sobre Habermas, véase Bernstein (1988:253 y ss.) 
Vol. XXI / № 1 / 2007 / 83-110

puede proteger la igualdad de derechos de cada cual sin hacer lo propio con el bien de todo próximo y de la comunidad de la cual forman parte (cf. Habermas 2000).

Sin embargo, ¿podemos hacer valer esa empatía solidaria y esta idea de justicia coapoyada en la solidaridad, sin al mismo tiempo revisar y transformar el tipo de lazo social que genera el actual proceso de modernización entre nosotros y sus fundamentos económico-sociales, construidos ellos, a decir verdad, a la medida de una sociedad capitalista que se sostiene en el individualismo, el egoísmo económico, la primacía del dinero y las leyes de la ganancia? ¿Será suficiente el recurso a la ética discursiva - y el principio de discusión - para promover cambios sociales que reorienten el proceso modernizador hacia mayores cuotas de justicia y solidaridad? Sobre este punto, Habermas permanece muy prudente o, más bien, escéptico de lo que pueda dar una política conducida por la ética para generar cambios históricos. Habermas es escéptico respecto a las posibilidades de modificar el rumbo de las lógicas sistémicas actuales, lo cual induce a muchos a preguntarse por su viabilidad también política en nuestra América, uno de los continentes con más desigualdad del mundo.

La asunción de una ética discursiva per se no puede llevarnos sin mediaciones hacia una conformación de prácticas sociales e institucionales urdidas desde los principios de una justicia solidarista. Eso sólo es factible mediante la acción de ciudadanos y ciudadanas en igualdad de condiciones, requisito fundamental para recuperar la presencia y fuerza de un poder comunicativamente fomentado y que de diversas maneras pueda traspasar y traducir demandas desde el mundo de la vida hacia los sistemas dinero y poder. Según Habermas, la pretensión de aplicar la ética discursiva sin mediaciones conduce a disparates. ${ }^{15}$

Ahora bien, descendiendo hacia la sociedad y su marcha, aunque no encontramos en esta visión de la ética una definición material determinada de la justicia (como tampoco de la solidaridad), trabaja allí un concepto implícito de ella. Podemos ligar esa noción implícita a lo que está presupuesto para el cumplimiento eventual, tanto de los principios $\mathrm{D}$ y U, como de la propia solidaridad, en las sociedades modernas. Por de pronto, una sociedad integrada no sólo sistémicamente sino también socialmente, será aquella en la cual todos sus miembros puedan ser eventualmente sujetos morales autónomos y dialogantes en relación a las decisiones y orientaciones fundamentales de la sociedad en la cual viven. En segundo término, una reflexión sobre la justicia tendría que tomar en cuenta no sólo las cuestiones ligadas a la distribución de bienes materiales, sino también al estado y porvenir de las relaciones sociales de reconocimiento. En tercer lugar, una sociedad más o menos justa e integrada tiene que luchar desde ya contra todas las formas de discriminación, exclusión, concentración de poderes, que impiden que cada uno de

15 De esto se han percatado buena parte de las éticas reflexivas hace ya tiempo. Las malas utopías siguen apostando por lo contrario. 
sus miembros sea reconocido como persona digna y como un fin en sí mismo; o, de otra manera, que cada uno de ellos pueda participar de manera no coercitiva y en igualdad de condiciones en los asuntos comunes que les afectan y en los discursos morales de interés común. Avanzar hacia el cumplimiento de esas posibilidades para los ciudadanos pide también desde la sociedad, al menos: a) un acceso igual a informaciones y tradiciones de formación que se revelan pertinentes para afirmar las tradiciones morales mediante el discurso argumentativo; b) el cultivo e impulso de reconocimiento social y de autoestima suficientes para que cada cual defienda las convicciones que tiene. Puesto de otra manera, la ética discursiva trabaja presuponiendo unas condiciones de justicia que la entienden como libertad igualitaria activa, como capacidad de ejercicio de derechos en igualdad de condiciones y con respeto por la condición humana de cada cual. Todo un programa para un proyecto político.

Con todo, ni la formulación ni el seguimiento de sus principios puede garantizar sus resultados. En la marcha de nuestras sociedades la normatividad vive asediada por los fenómenos de violencia de distinto tipo, desigualdad, manipulación y engaño, de uso abusivo del poder, de ideologización. Habermas es consciente de ello y en eso le ha ayudado un Hegel. Los discursos prácticos —es decir, aquellos en los cuales está implícita una disputa por la significación y el sentido de términos como justicia, equidad, igualdad, democracia, derechos humanos, poder — poseen o soportan una presión social sobre sí diferente a la que soportan los discursos explicativos y teóricos. El debate y deliberación dialógico-argumentativo en torno a normas no es una taza de leche: "la lucha de las normas, aunque se lleve a cabo con medios discursivos, sigue estando enraizada en la lucha por el reconocimiento" (1985:131), con lo cual el pretendido idealismo y abandono de las condiciones históricas de realización de normas queda mitigado. El diálogo, interacción y debate argumentativo en torno a normas no se efectúa entre humanos angelizados en una apacible tarde de domingo. Por eso Habermas afirma que

los discursos prácticos, como todas las argumentaciones, se parecen a islas amenazadas de inundación en el mar de una praxis en el que no domina en absoluto el modelo de resolución consensual de los conflictos de acción. Los instrumentos de la violencia reprimen siempre los medios del entendimiento. (1985:131)

Es de lamentar que Habermas no haya seguido más de cerca —en su evolución reflexiva de esta temática-, esta intuición capital y aún válida.

Desde este punto de vista, Habermas sabe que el filósofo moral no está por sobre las capacidades del conjunto de la sociedad, ni que puede por sí y ante sí modificar el estado de cosas actual. Las tareas comprensivas y de transformación de los poderes e instituciones, en función de la creación de condiciones donde sea factible esta manera de construir comunidad-sociedad, le pertenecen a todos los ciudadanos. Es a ellos (como sociedad 
civil, ciudadanía asociada y autoorganizada), y no a un macrosujeto vanguardístico o a la iluminación aislada de un profeta, a quienes corresponden estas tareas. Vistas así las cosas, el enfoque de Habermas incluye también en la dimensión normativa la cuestión política, toda vez que no abre un abismo entre los asuntos práctico-morales y los público-políticos, o entre individuo y sociedad.

Ahora, como hemos dicho más arriba, la concreción histórica de reivindicaciones éticas es una tarea que no puede realizar en forma directa y por sí misma la ética discursiva y sus principios orientadores. Entra entonces a jugar su rol el principio de discusión, la política y el derecho. Por cierto, en este caso, no cualquier política ni cualquier derecho. Tienen que diseñarse en complementación y mediación de los principios de esa ética discursiva, y al mismo tiempo tomar en cuenta las realidades del tiempo presente para ambos espacios de acción. En lo relativo al modo en que Habermas ve las posibilidades de la acción política, él quiere rescatarla de las aguas de la mera estrategia o del puro tecnocratismo o, incluso, de la sola legalidad. Pero, claro, no se trata en su visión de volver a una idea de política como la que alimentaba la ciudad-estado griega, o de reponer un nuevo ideario unificador y orientador valórico para la marcha de las instituciones, como lo sugiere el republicanismo. Tampoco se trata de limitarse a la visión liberal de la política y el estado. Su ideal de política deliberativa aparecerá tensionado en dirección de lo que Habermas llama democracia radical, es decir, la ampliación y profundización del poder comunicativo que radica en la soberanía de ciudadanos mediada procedimentalmente. Con ello,

el poder generado comunicativamente puede obrar sobre las premisas de los procesos de evaluación y decisión de la administración pública sin intención alguna de proceder a su conquista, con el fin de hacer valer sus exigencias normativas en el único lenguaje que la asediada fortaleza entiende: proveer el arsenal de razones que el poder administrativo tratará, desde luego, de manejar instrumentalmente pero a las que, mientras ese poder esté articulado en términos de Estado de derecho, no podrá ignorar en su sustancia. (1991a:283)

Con todo, una idea de democracia deliberativa no quiere verse simplemente como una mera negación de las formas y contenidos políticos conocidos hasta ahora, sino que pretende superar — conservando - lo mejor y más adecuado del modelo liberal y republicano. Por un lado, quiere rescatar del modelo liberal —entendido como coordinación de intereses privados contrapuestos-, la salvaguarda que allí se da entre los derechos sujetivo-individuales, en lo cívico-político, pero reinsertarlos desde otra perspectiva: la del poder comunicativo y la soberanía popular procedimentalizada. El modelo republicano, por su parte, es uno que pretende, justamente contra la óptica liberal, revitalizar el compromiso cívico-ciudadano fuerte con su propia democracia y política, a base de convicciones y virtudes ciudadanas. 
El ideario de una política y democracia deliberativas quiere conjugar la libertad de los modernos (libertad de creencias, libertades personales, protección de la vida, propiedad), y la libertad de los antiguos (derechos de participación y de comunicación política que apuntan hacia la autodeterminación de los ciudadanos, libertades positivas) (Habermas, Rawls 1998:66 y ss.), en función de la expresión plural de formas de comunicación que pueden llegar a constituir una voluntad común, mediante el equilibrio de intereses, la elección racional de medios, las justificaciones morales, etc. Habermas criticará la idea de la política que promueve el liberalismo, la cual arranca del supuesto de que los individuos poseen intereses propios y distintos, y que compiten entre sí para alcanzar sus metas (privadas). El proceso democrático es visto como orientado a 'programar el estado en interés de la sociedad'.

Por su parte, la política es entendida como trabajo de coordinación de intereses sociales privados que pone en el estado la tarea de administración y vigilancia de su realización y mutuo resguardo. Aquí lo significativo es que las relaciones que se establecen entre sociedad, estado y mercado están marcadas y mediadas por una lógica estratégica, en la cual subyace la visión de que en la sociedad se libra un permanente conflicto de intereses de los individuos que luchan por su propia felicidad, donde cada cual, por cierto, define su objetivo y sus estrategias para conseguir sus fines, y en el que 'el otro' es visto normalmente como un contrincante (Habermas 1999:231 y ss.).

Por el lado republicano, la política no es sólo mediación de intereses y visiones contrapuestas. Ella se entiende como forma de reflexión de un contexto de vida ético, como el medio a través del cual los miembros de comunidades solidarias dan cuenta de su mutua dependencia, y como ciudadanos desarrollan y conforman con voluntad y conciencia relaciones de reconocimiento recíprocos, convirtiéndolas en asociaciones de miembros libres e iguales en medio de una comunidad jurídica. A diferencia del liberalismo, acá aparecen la solidaridad y la orientación por el bien común como una tercera fuente de integración social. Por ello, en una idea republicana de la política, el espacio público y su propia base, la sociedad civil, adquieren gran importancia, toda vez que aseguran la práctica del entendimiento intersubjetivo de los ciudadanos y su capacidad de integración y autonomía (Habermas 1998:342 y ss).

Si bien Habermas valora estos elementos definitorios del republicanismo político, no los sigue completamente y toma distancia de ellos. En particular, crítica al republicanismo el entender la política como una autocomprensión centralmente ética y, con ello, el estrechamiento ético al que somete los discursos públicos. No es conducente esta forma de entender la política en la actualidad, debido a la fuerza del pluralismo político, social y cultural presente en nuestras sociedades. Como puede haber intereses contrapuestos y conflictuados, no es posible dejar fuera las negociaciones y la acción estratégica. En su idea de política deliberativa, el proceso mismo de formación de la voluntad común en tanto voluntad política se podrá conformar entreverando discursos pragmáticos (estratégicos), ético-políticos y morales. Lo importante aquí es que el peso se pone en el ejercicio 
Vol. XXI / № 1 / 2007 / 83-110

de una racionalidad comunicativa y en los procedimientos a distintos niveles mediante los cuales se legitiman decisiones, procesos, normas (legales) e instituciones, a partir de la opinión y voluntad políticas de los ciudadanos. ${ }^{16}$

Para esta teoría se trata de ir más allá de las expresiones liberal-republicanas, y que su basamento del accionar público-político sea en una totalidad social centrada en el estado o en una coordinación anónima a la ley de sujetos particulares vistos como competidores entre sí. Lo que aquí se realza son los procesos de entendimiento sea en la forma institucionalizada de deliberaciones en el Parlamento o en la red de comunicación sostenida en la esfera política y la opinión pública. Es decir, que esa deliberatividad sea conducida por procesos formales o por expresiones informales; una más ligada a la institucionalidad vigente, la otra más conectada con la formación informal de una opinión pública, allende los mecanismos establecidos de mediación de los poderes. En ambos casos, esos procesos de entendimiento expresarían una intersubjetividad de orden superior, en la que juega un rol importante la sociedad civil, diferenciada tanto del sistema económico como del poder organizado administrativamente.

La política deliberativa trabaja entonces en el cruce de la interacción entre la formación democrática de la voluntad y una formación informal de la opinión. Por lo mismo, no se autoencierra de manera autárquica en las vías establecidas de una deliberación y las decisiones reguladas acorde a procedimientos, porque el proceso de formación de la voluntad democrática resulta necesariamente incompleto e inacabado. Por ello, para mantenerse vivo y vital tiene que renovarse de manera permanente, y ello no es factible sino mediante la asociatividad ampliada, incluida la opinión pública, la cual proporciona y alimenta con argumentos y elementos las reflexiones pertinentes para una política deliberativa que tenga en cuenta tanto la complejidad del sistema como los complejos mecanismos de integración social. Por cierto, esta política deliberativa y sus presupuestos comunicativos no poseen como contraparte alguna forma concreta de realización de la democracia o un determinado modelo histórico de sociedad.

Desde este punto de vista, los principios y presupuestos de la ética discursiva, su traducción generalizada como principio de discusión, no dibujan un modelo concreto de política y sociedad, sino que colocan los ingredientes y elementos que permiten - contrafácticamente- profundizar desde ya la marcha de las democracias realmente existentes y la intercomunicación entre los subsistemas entre sí, todo ello con vistas a preservar los ingredientes comunicativos de una integración social, y el eventual protagonismo de ciudadanos y sociedad civil en la marcha general de las sociedades. Es decir, mantener o preservar 'el lugar de posible fisura o ruptura que representa este poder decir que no', enmarcado en el ejercicio de la acción comunicativa y procesos de entendimiento

16 Véase Habermas (1999); también Habermas (1998:372 y ss.); para la polémica con Rawls respecto a varios de estos puntos, ver Rawls y Habermas (1998). 
discursivo. Aunque ello suene a poco, representa un contrafuerte argumentativo para modelos de modernización enclavados en una antropología individualista, hostil al desarrollo de estructuras comunicativas intersubjetivas y replegados sobre consideraciones axiológicas egoístas, cuando no etnocentristas.

Por sí misma, la ética discursiva no puede aplicarse a la sociedad y sus instituciones sin mediaciones. Debido a ello requiere ser mediada y distinguida de un principio generalizado de discusión, que puede actuar en cuestiones legal-jurídicas, como político-pragmáticas siguiendo la idea matriz que hace depender la validez de las normas de acción del asentimiento de aquellos que, como afectados, participan en discursos racionales. Como lo hemos visto, el tránsito hacia la generalización en un principio de discusión muestra una inflexión en el trabajo habermasiano, por medio de la cual las determinantes ético/morales se ponen ahora como un rasgo propio de un desarrollo democrático; por ese medio se busca una cierta eficacia práctica para ellos. Principio de discusión, política deliberativa y democracia radical representan el movimiento de continuidad y ruptura de la mediación de los presupuestos y principios centrales de la ética discursiva, respetando las distintas lógicas de los campos de acción social.

Es muy probable que la desilusión que provoca la transformación real del capitalismo liberal (caída de los socialismos reales, por ejemplo), y la conciencia de la dificultad de modificar radicalmente la marcha autonomizada de los subsistemas (dinero y poder), es decir, de modificar estructuralmente el dominio capitalista, hayan llevado a Habermas a revalorizar el rol del derecho. Una vez que las posibilidades y quizá la propia necesidad de aspiraciones revolucionarias quedan sepultadas bajo los escombros de las resultantes del siglo XX, el derecho aparece como un mediador valioso para propugnar un reformismo radical, uno que tiene en la sociedad civil y los movimientos sociales su principal punta de lanza para abrir una posibilidad permanente de cuestionamiento desde los mundos de vida hacia los subsistemas dinero y poder. Esto requiere, claro está, la movilización de las libertades comunicativas de los ciudadanos. El derecho manifiesta su doble cara: por un lado, apegado a la razón de estado prevaleciente, formalizado y positivizado; por el otro, en permanente apertura hacia las reivindicaciones de legitimación que provienen del poder comunicativo. El derecho se vuelve un medio vía el cual el poder comunicativo se transforma en poder administrativo.

El último Habermas, si podemos hablar así, tiene ya menos confianza en que seamos capaces de generar cambios radicales en el modo de producir y reproducir las sociedades tal como son. Sin embargo, mediante su ética discursiva su ideal de política deliberativa, el principio de discusión y el derecho como mediación social de facticidad y validez, reafirma una esperanza siempre abierta en que no nos queda sólo decidir, sino también — siempre - deliberar. Su idea de una moral, una política deliberativa y un derecho, profundamente inspirada por un ideal de democracia radical, nos aporta también para examinar los aspectos más ambiguos del sistema de democracia representativa (en cuestionamiento), oponiéndole la necesidad de complementarlo con medios de expresión 
de una democracia real. Una que esté sostenida en el ideal de legitimidad republicana ejercida por una comunidad de decisión que, respetando el pluralismo y las propias reglas de una discusión democrática, es pensada como una comunidad de ciudadanos que tienen el mismo derecho a participar en los procesos colectivos de formación de la voluntad política.

Para Habermas, entonces, pareciera que el único camino que tenemos para renovar y estabilizar la democracia realmente existente fuese a través de un movimiento desde dentro de ella misma, es decir, por la recreación y ampliación de un espacio público no sometido a los poderes fácticos, y por medio de un sistema de derecho que no está cerrado sobre sí mismo, sino que también se alimente — como hemos visto más arriba— del ejercicio de una moral social democrática de ciudadanos y de una cultura democráticoliberal que impulse su desarrollo. En este proyecto se trataría de que la dimensión normativa no desaparezca bajo las heladas aguas de las lógicas unilaterales de los subsistemas o de la facticidad del orden social. Una tarea nada fácil ni simple. Una tarea que a cada paso encuentra detractores tanto en los procesos concretos de globalización modernizante como en aquellas perspectivas (sociológicas, filosóficas, políticas) que descreen de toda posibilidad para la razón y la acción de levantar un horizonte de posibilidades distinto al actual. A pesar de las dificultades que tiene la posición habermasiana - y que él mismo ha ido trabajando-,${ }^{17}$ abre la esperanza de reencontrar un espacio legítimo para una dimensión normativa y una reivindicación de lo ético/moral, más allá de todos los proclamados y diversos naufragios. Para los tiempos que corren esto no es poco.

\section{Referencias bibliográficas}

Apel, Karl-Otto, 1985. "El a-priori de la comunidad de comunicación". Transformación de la filosofía. Vol. II. Barcelona: Taurus. 1986. Estudios éticos. Barcelona: Alfa.

1991. Teoría de la verdad y ética del discurso. México DF, Buenos Aires: Paidós. Benhabib, Seyla, 2006. El ser y el otro en la ética contemporánea. Barcelona: Gedisa. Bernstein, R.J., ed., 1988. Habermas y la modernidad. Madrid: Cátedra. Cortina, Adela, 1989. "La ética discursiva”. Historia de la ética. Vol. III. Barcelona: Crítica. Gilligan, Carol, 1994. La moral y la teoría. México DF: Fondo de Cultura Económica. Habermas, Jürgen, 1985. Conciencia moral y acción comunicativa. Barcelona: Península. , 1987. Teoría de la acción comunicativa. 2 vols. Madrid: Taurus. 1989. Problemas de legitimación del capitalismo tardio. Buenos Aires: Amorrortu. , 1991a. La necesidad de revisión de la izquierda. Madrid: Tecnos.

17 Véanse los comentarios de Habermas (2000) a varios abordajes críticos de su propuesta (127 y ss.) 
, 1991b. Escritos sobre moralidad y eticidad. Barcelona, Buenos Aires: Paidós.

, 1991c. “¿Afectan las objeciones de Hegel a Kant también a la ética del discurso?” Escritos sobre moralidad y eticidad. Barcelona, Buenos Aires: Paidós, 101-131.

, 1991d. "Justicia y solidaridad". En Adela Cortina, Julio de Zan, Dorando J. Michelini, eds. Ética comunicativa y democracia. Madrid: Crítica.

, 1993 (1989). El discurso filosófico de la modernidad. Madrid: Taurus.

1998. Facticidad y validez. Madrid: Trotta.

, 1999. "Tres modelos normativos de democracia”. La inclusión del otro. Barcelona, Buenos Aires: Paidós, 231-246.

, 2000. Aclaraciones a la ética del discurso. Madrid: Trotta.

Habermas, Jürgen, John Rawls, 1998. Debate sobre el liberalismo político. Barcelona: Paidós.

Heidegger, Martin, 1986. Perfiles filosófico-politicos. Madrid: Taurus.

Kohlberg, L., 1992. La psicología del desarrollo moral. Bilbao: Desclée de Brouwer.

Mead, G.H., 1968. Espíritu, persona y sociedad. Barcelona, Buenos Aires: Paidós.

Rawls, John, 1979. Teoría de la justicia. México DF: Fondo de Cultura Económica.

Rorty, Richard, 1988. "Habermas y Lyotard sobre la postmodernidad”. En R.J. Bernstein, ed. Habermas y la modernidad. Madrid: Cátedra

1991. Contingencia, ironía y solidaridad. Barcelona: Paidós.

Salvat, Pablo, 2000. Informe al "PNUD-Chile: Del proceso de modernizaciones y las transformaciones normativas en la sociedad chilena". Documento de trabajo. 